\title{
Prover e acumular: a estrutura e o perfil da posse de escravos em um contexto econômico de abastecimento (São Luiz do Paraitinga no primeiro quartel do XIX)
}

\section{Diego Alem de Lima}

DOI: 10.11606/issn.2318-8855.v10i1p299-330

Resumo: O presente trabalho foi desenvolvido com o principal objetivo de estabelecer uma análise acerca do uso e da posse da mão de obra escravizada em um contexto econômico de abastecimento durante o período colonial brasileiro, em uma vila paulista não diretamente relacionada às atividades exportadoras da colônia: a pequena São Luiz do Paraitinga, localizada no médio Vale do Paraíba. A partir da rica documentação das Listas Nominativas de Habitantes disponíveis para o intervalo entre 1798 e 1818, bem como do instrumental teórico e metodológico da Demografia Histórica, buscamos acessar a faceta escravocrata do universo socioeconômico da pequena povoação, partindo de uma temática pouco usual nos trabalhos sobre a escravidão colonial: os pequenos proprietários de escravos. Assim, observando, ano a ano, os longos Maços de População, fomos capazes de mapear centenas de trajetórias individuais que, em conjunto, pavimentaram o caminho para o aprofundamento das questões propostas: qual é a importância demográfica do setor de pequenos proprietários de escravos? Quais são as características sociais e demográficas desses indivíduos? E aquela que talvez tenha sido a questão central: quais são as características e o perfil da composição dessas escravarias? As respostas obtidas apontam para um quadro que difere em grande medida de alguns consensos préestabelecidos pela historiografia existente, e serão, a seguir, apresentadas.

Palavras-chaves: Escravidão, História do Brasil, Demografia Histórica, Economia de Abastecimento, Brasil Colonial. 


\section{artigos}

Diego Alem de Lima

A presente pesquisa teve como principal objetivo analisar a posse de escravos na vila colonial de São Luiz do Paraitinga durante a primeira metade do século XIX (1798-1818), a fim de compreender como o fenômeno da escravidão se desenvolveu em um contexto econômico de abastecimento, a partir da investigação das trajetórias de vida de indivíduos e de seus respectivos domicílios presentes nas listas nominativas de habitantes disponíveis para a localidade.

Como pondera Valter Martins, boa parte da historiografia clássica dispensou poucas atenções para as regiões do país dedicadas aos mercados internos de abastecimento, tratando os pequenos agricultores e produtores como secundários e pertencentes a um universo econômico vazio e pouco significativo (1996, P.16). Há, ainda, entre os historiadores tradicionais, aqueles que voltaram seus olhares e esforços para essas esferas preteridas da população, como Caio Prado Junior. Entretanto, mesmo nesses casos, o discurso predominantemente reproduzido é aquele que conceitua a dinâmica abastecedora como atividade marginal, residual.

Porém, como bem tem demonstrado a historiografia recente acerca do passado colonial paulista, as atividades econômicas de abastecimento preencheram um espaço importante no universo dos habitantes da capitania/província, principalmente no transcorrer do século XVIII, quando diversas localidades paulistas passaram a fornecer 


\title{
artigos
}

\section{Prover e acumular}

suprimentos às recém-descobertas paragens mineradoras. Ao contrário do que preconizava a antiga tradição historiográfica ${ }^{1}$, as recentes teses, colhendo os frutos das novas metodologias e arcabouços teóricos ${ }^{2}$, defendem que já existia em São Paulo uma importante rede mercantil durante os séculos XVII e XVIII, baseada nas trocas envolvendo gêneros de abastecimento. A abertura do chamado "Ciclo da Mineração" teria tido como consequências as profundas alterações econômicas e demográficas vivenciadas pela capitania paulista ao longo dos setecentos, a saber: aumento considerável no número de habitantes, abertura e ocupação de áreas antes inexploradas e surgimento de novas atividades econômicas (MARCÍLIO, 2000). Já de acordo com Luna e Klein:

\begin{abstract}
"A historiografia recente começou a revelar a importância cada vez maior da pequena produção agrícola local de gêneros alimentícios no contexto brasileiro como contraponto à ênfase na grande lavoura na literatura tradicional. Na maioria das áreas, a produção destinava-se à subsistência e à venda em mercados locais e regionais. Sempre provinha da unidade agrícola familiar, mas com frequência incluía empregados e escravos; no caso de São Paulo antes de 1700, esses cativos eram índios. O uso da mão de obra escrava, inicialmente de índios e depois de negros, para produzir gêneros de subsistência e destinados ao mercado local, foi uma das características distintivas da escravidão brasileira. Poucas foram as outras sociedades escravistas nas Américas que fizeram uso tão sistemático da cara mão de obra escrava nessa área de produção." ( 2006).
\end{abstract}

Entretanto, ainda que a relevância econômica e social dos mercados de abastecimento não tenha sido de todo ignorada pela historiografia, estudos detalhados acerca das dinâmicas e estruturas humanas que caracterizaram tais localidades se mostram extremamente raros (BACELLAR, 2001, p. 143). Mais do que isso, embora

\footnotetext{
1 Para estudos clássicos sobre São Paulo colonial, ver: TAUNAY, Affonso de Escragnolle. História Geral das bandeiras paulistas. São Paulo: H.L. Canton, 1949; CANABRAVA, Alice Piffer. O desenvolvimento da cultura do algodão na província de São Paulo, 1861-1875. Universidade de São Paulo, 1951. ELLIS JÚNIOR, Alfredo. Raça de Gigantes: a civilização no planalto paulista. São Paulo: Helios, 1926

2 Destacam-se as abordagens no campo da Demografia Histórica, que introduziram a utilização de novos conjuntos documentais, sobretudo o de fontes seriais.
} 


\section{artigos}

Diego Alem de Lima

tenham se multiplicado, a partir da década de 1970 (MOTTA, 1988), os estudos centrados na posse de escravos em São Paulo colonial, a maioria desses esforços se deram no sentido de compreender o funcionamento da máquina escravista em zonas ligadas mais diretamente às consagradas redes exportadoras.

A vila de São Luiz do Paraitinga (localizada no Vale do Paraíba), mesmo durante o século XIX, quando as principais culturas exportadoras tomavam vulto em diferentes regiões da província(LUNA; KLEIN, 2006), manteve-se em grande medida como uma localidade especializada no abastecimento regional. A produção local, centrada em produtos como o tabaco, o algodão e a criação de suínos, sempre se destinou a suprir as demandas regionais em cidades como Paraty, Ubatuba e Rio de Janeiro. Assim, nossos esforços buscaram cumprir uma dupla tarefa. Em primeiro lugar, levantar indícios e dados acerca da complexa formação demográfica dos pouco conhecidos rincões abastecedores. E, em segundo lugar, de levantar apontamentos sobre as diferentes estratégias e mecanismos que possibilitavam aos habitantes dessas isoladas vilas acumularem, ao longo de sua trajetória, algum cabedal econômico na forma de escravos.

Foram alvos de investigação não os poucos grandes proprietários, costumeiramente investigados pela historiografia, mas sim a ampla e majoritária camada de pequenos produtores e elementos urbanos, que predominavam no espectro demográfico da vila, incluindo também artesãos e comerciantes. Dessa forma, pretendeu-se observar os esforços e estratégias desenvolvidos por esses setores da população, sobretudo o primeiro deles, para a obtenção de cativos, transformando-se em pequenos senhores e diferenciando-se da imensa maioria dos habitantes da vila, que jamais viria a possuir plantéis, ainda que diminutos, de escravos. 


\section{artigos}

\section{Prover e acumular}

Acreditamos que o estudo da estrutura da posse de escravos em uma comunidade colonial é crucial para a compreensão da forma pela qual a riqueza se distribuía em tais sociedades, posto que a mão de obra cativa figurava entre os seus principais fatores de produção, ao lado do próprio trabalho familiar.

Como supracitado, as fontes utilizadas para a análise do universo da vila de São Luiz do Paraitinga foram as listas nominativas de habitantes. A confecção de tais maços de população se insere em um cenário de reformas administrativas de cunho mercantilista, introduzidas pela Coroa portuguesa sob a égide pombalina. 0 recrudescimento dos infindáveis conflitos contra os castelhanos na região do Prata, bem como a necessidade de se reorganizar e estimular a diversificação da produção agrícola no bojo das dificuldades econômicas vivenciadas pela metrópole na segunda metade do século XVIII (NOVAIS, 1995), foram, respectivamente, as molas mestras que guiaram as orientações para a produção das listas. Como sugere Maria Luiza Marcílio, o primeiro período de manufatura das listas seria marcado por fortes preocupações militares da burocracia régia. Já o segundo momento, caracterizado pela autora como "a fase de aperfeiçoamento dos recenseamentos" (1797-1830), teria como mais salientes as diretrizes voltadas ao desenvolvimento econômico:

\footnotetext{
"Os constantes problemas das fronteiras do extremo-sul, e também na Amazônia, entre as terras das Coroas de Espanha e de Portugal, ora criando conflitos armados nas zonas disputadas, ora sendo discutidos em âmbito diplomático na Europa, exigiam de Portugal constante prontidão e preparo de tropas e de milícias da terra para defender suas possessões. A Capitania Paulista, por ser a mais próxima da região sul disputada, era solicitada com mais frequência, sobretudo depois de 1740 ...Por isso, os levantamentos censitários que começaram a ser realizados na segunda metade do século XVIII visavam responder a objetivos militares. Por meio deles podiam, a Metrópole e seus funcionários na Colônia, conhecer o número de adultos disponíveis para armas."(MARCíLIO, 2000).
}

Ainda de acordo com a autora, sobre os lustros finais do século XVIII:

"A partir de 1797, a classificação etária da população passou a ser uniforme, com intervalos quinquenais até os dez anos e decenais daí para Epígrafe, São Paulo, v. 10, n. 1, pp. 299-330, 2021 


\section{artigos}

\section{Diego Alem de Lima}

cima, tanto para os homens quanto para as mulheres. As tabelas gerais da população deveriam combinar varias características demográficas (sexo, idade, estado civil, cor) cruzando-as em quadros que levavam ainda em consideração a condição social (livres e escravos).

Nessa nova fase dos censos brasileiros, os objetivos passaram a ser menos militares, e mais econômicos e de política populacional" (MARCÍLIO, 2000, p.39)“

O responsável por instaurar a prática dos recenseamentos no território paulista foi o então governador, o Morgado de Mateus, a partir de 1765. O levantamento passou a ser realizado anualmente pelas divisões militares das Companhias de Ordenanças. As listas feitas pelas companhias de cada vila possuem, em geral, uma primeira divisão por freguesias e bairros. Sua confecção buscou trazer a quantidade de fogos existentes na vila, assim como o nome dos moradores: nomes do chefe de família e sua esposa, geralmente os nomes acompanhados dos sobrenomes com indicação da patente militar daquele (quando existente), e idade de ambos; quanto aos filhos, apenas primeiro nome, idade e naturalidade. No que diz respeito aos agregados, por vezes apareciam com nome completo, idade e naturalidade. Com relação aos escravos, indicava-se apenas a quantidade total em alguns casos; em outros poucos, os nomes, idade, estado civil e naturalidade. Em nossa pesquisa, foram utilizadas onze listas nominativas referentes ao intervalo selecionado (1798-1818), e um total de 1200 domicílios pôde ser coligido e analisado.

\section{Quadro Social e Estrutura da posse de escravos: 1798-1818.}

Apesar de ser uma das regiões de povoamento mais antigo de que se tem notícia para a história paulista, até meados do século XVIII, alguns rincões isolados do Vale do Paraíba permaneceram alheios à ocupação humana. O local onde hoje se encontra a pequena cidade de São Luís do Paraitinga nos serve para exemplificar um desses casos. Apenas com a restauração da autonomia administrativa da então capitania paulista, no 


\section{artigos}

\section{Prover e acumular}

ano de 1765, decidiu-se povoar a área compreendida entre o Vale e o litoral, região drenada pelos rios Paraitinga e Paraibuna (SAIA; TRINDADE, 1977).

Em trabalho pioneiro sobre a pequena vila colonial, Jaelson Trindade e Luís Saia afirmam que o povoamento da região do Paraitinga deve ser compreendido como uma das consequências da abertura do Caminho Novo, que ligou diretamente as zonas mineradoras ao Rio de Janeiro, concluído entre os anos 1780 e 1790 (SAIA; TRINDADE, 1977). A nova via teria feito com que as antigas rotas de ligação, que passavam pelo Vale, deixassem de ser frequentadas pelos comerciantes e viajantes, e os antigos moradores que ocupavam a região teriam sido compelidos a buscar novas alternativas de sobrevivência, sobretudo buscando áreas para desenvolver a lavoura de subsistência. Ademais, a política empreendida pelo Morgado de Mateus tinha como uma de suas principais diretrizes a fundação de novas vilas, visando um aumento da produção e, consequentemente, da arrecadação por parte do aparato estatal (MONT SERRATH, 2017).

Assim, a origem do pequeno povoamento teria ligações com a migração de pequenos sitiantes e produtores, posseiros, que plantavam e criavam para a própria subsistência. O relevo extremamente acidentado que caracteriza a região, bem como a ausência de jazidas minerais que despertassem o interesse em sua exploração econômica, teriam feito com que a povoação mais sistemática da região se desse apenas com a chegada do café ao Vale, já próximo à segunda metade do século XIX. Até então, as pequenas comunidades e aglomerados populacionais ali instalados se caracterizavam pela quase exclusiva lavoura de subsistência, que no caso de São Luís, baseou-se, inicialmente, no plantio de milho e feijão (PETRONE, 1959, p.251).

Esse povoamento rarefeito e baseado na pequena produção para consumo interno caracterizou a vila durante os anos aqui analisados, bem como o predomínio de 


\section{artigos}

Diego Alem de Lima

pequenas propriedades policultoras, dedicadas ao cultivo de gêneros para a subsistência, como arroz, milho, tabaco, feijão e toucinho.

Entretanto, desde o início de nossas análises foi possível identificar a existência de um comércio de excedentes, sobretudo voltado à venda de alguma quantidade de açúcar, tabaco e porcos vivos.

Em 1798, foram listados apenas 379 domicílios, número pequeno se comparada com vilas vizinhas, como Lorena, que em 1804 já contava com mais de 1100 fogos listados. Mais do que isso, no decorrer do período analisado, São Luís não apresenta crescimento acelerado no número de fogos, o que pode ser um efeito do relativo isolamento econômico da vila em relação às grandes atividades de exportação.

\begin{tabular}{|c|c|c|c|c|c|c|c|c|c|c|c|}
\cline { 2 - 10 } \multicolumn{1}{c|}{} & 1798 & 1799 & 1802 & 1804 & 1806 & 1808 & 1810 & 1812 & 1814 & 1816 & 1818 \\
\hline $\begin{array}{c}\text { Domicílios } \\
\text { Listados }\end{array}$ & 379 & 425 & 439 & 439 & 445 & 482 & 488 & 526 & 503 & 475 & 530 \\
\hline
\end{tabular}

Tabela 1: Domicílios listados ano a ano. Fonte: Listas Nominativas de Habitantes de São Luiz do Paraitinga (1798-1818)

Porém, ainda que relativamente isolada das principais teias mercantis exportadoras da colônia e dependente dos núcleos regionais para a comercialização da produção sobressalente, a economia de São Luís do Paraitinga se mostrou, ao longo do período analisado, portadora de um grau de dinamismo capaz de possibilitar a acumulação de capital na forma de escravos por parte de uma parcela de sua população. Havia, em 1798, 583 cativos listados nos domicílios da paróquia; dez anos depois, em 1808, já eram 793 os indivíduos escravizados; no último ano da série analisada, o número atingiu o total de 977 cativos. 
Prover e acumular

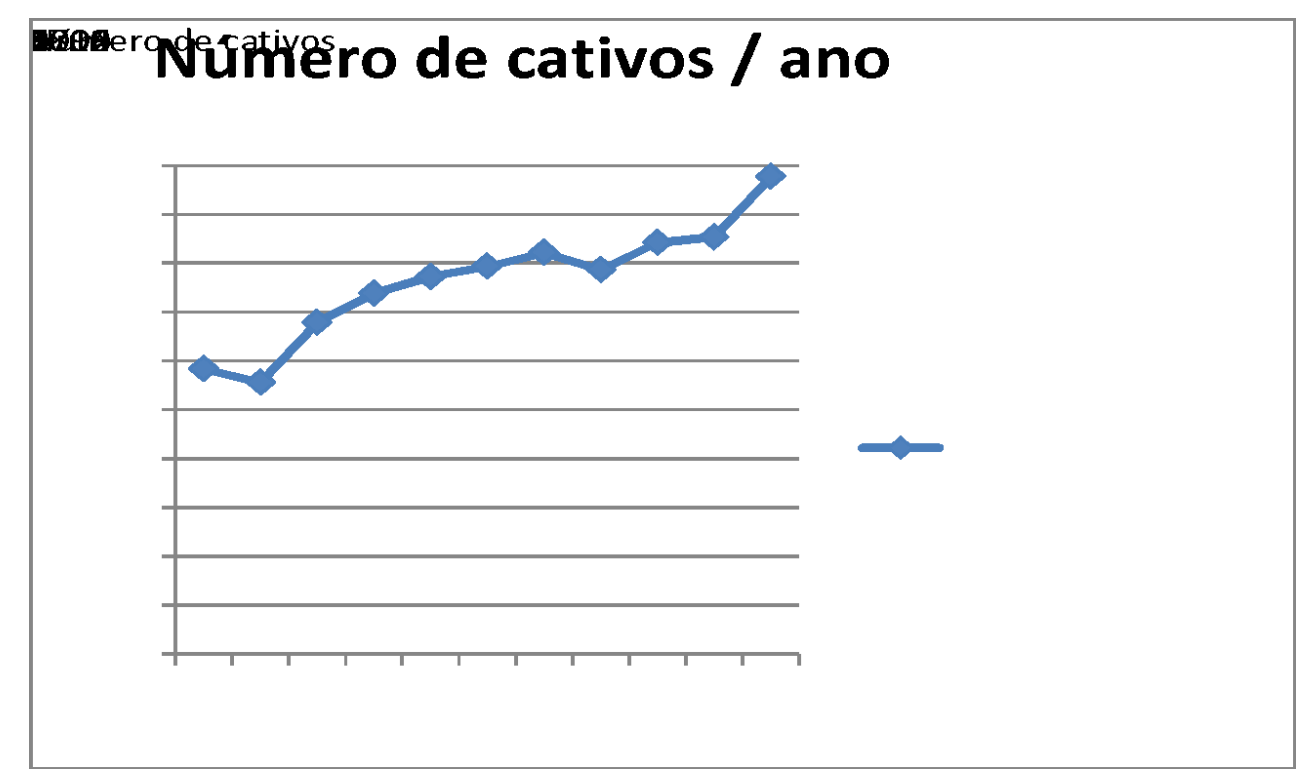

Gráfico 1. Fonte: Listas Nominativas de Habitantes de São Luiz do Paraitinga (1798-1818)

Percebe-se que, no decurso das duas primeiras décadas do século XIX, a população cativa da pequena vila se ampliou de forma consistente. Mais do que isso, o número de domicílios listados como possuidores de mão de obra escrava também aumentou significativamente ao longo do tempo. Eram 102 domicílios escravistas em 1798, passando para 125 em 1808, e chegando a 143 fogos possuidores de cativos em 1818.

Entretanto, tal crescimento não parece ter sido acompanhado por uma distribuição do acesso à mão de obra escrava no tecido social. A proporção de domicílios escravistas em relação ao total de fogos listados permaneceu quase inalterada ao longo de todo o período, variando em torno dos $25 \%$ da população livre listada, o que é um indício de que a acumulação de capital na vila teria se dado de forma concentrada. Tal proporção se aproxima da encontrada por Francisco Vidal Luna como média de proporção de domicílios escravistas em todo o Vale do Paraíba à época: $24,17 \%$ dos domicílios eram proprietários de escravos, em 1804 (LUNA, 1998, p. 114). 


\section{artigos}

Diego Alem de Lima

A taxa de aproximadamente $25 \%$ para a parcela relativa aos proprietários de escravos no seio da pequena vila é um dado que nos permite avançar sobre a realidade do universo cotidiano da paróquia. Desprovida das condições necessárias para ter acesso ao mercado negreiro, a esmagadora maioria de sua população depositava na mão de obra familiar as esperanças e expectativas para suprir as necessidades diárias. Pequenos roceiros e roceiras, cultivando suas roças rústicas que bastavam para seu próprio sustento e, eventualmente, possibilitavam a extração de pequenos excedentes. Cenário semelhante foi encontrado por Bacellar, ao estudar a vila de Sorocaba nos séculos XVIII e XIX (BACELLAR, op cit, p.133).

Mas é preciso delinear, ainda que brevemente, o quadro da distribuição dos escravos em relação aos plantéis para que possamos compreender de forma mais abrangente a dinâmica escravista da pequena paróquia. Durante todo o intervalo analisado, os pequenos plantéis representaram a esmagadora maioria numérica do total das escravarias inventariadas. Quadro este que é semelhante ao encontrado por outros estudiosos da escravidão paulista. José Flávio Motta, ao analisar a disseminação da lavoura cafeeira em Bananal durante a primeira metade do século XIX, atesta quadro semelhante, no qual os pequenos proprietários de escravos aparecem como fatia majoritária entre o total dos senhores, sobretudo na primeira fase da introdução da lavoura da rubiácea (MOTTA, 1991).

Não é escusado lembrar que, aqui, optamos por dividir os plantéis da vila em duas faixas distintas de tamanho: foram considerados como pequenos plantéis os que declararam possuir até 5 cativos; médios e grandes plantéis foram aqueles que apresentaram um número igual ou superior a 6 escravos. Preferimos não empregar as tipologias já consagradas, como a de Ricardo Salles, em nossas análises, posto que o 


\section{artigos}

Prover e acumular

universo aqui explorado destoa bastante da natureza das zonas monocultoras, onde tais classificações adquirem maior representatividade (SALLES, 2008).

\begin{tabular}{|c|c|c|c|c|c|c|c|c|c|c|c|}
\cline { 2 - 16 } & \multicolumn{10}{c|}{ Número de plantéis para cada categoria / an0 } \\
\cline { 2 - 14 } & 1798 & 1799 & 1802 & 1804 & 1806 & 1808 & 1810 & 1812 & 1814 & 1816 & 1818 \\
\hline Pequenos plantéis & 75 & 77 & 75 & 88 & 88 & 87 & 78 & 82 & 86 & 78 & 94 \\
\hline Médios e grandes $(>5)$ & 27 & 23 & 31 & 38 & 33 & 35 & 41 & 42 & 41 & 44 & 49 \\
\hline
\end{tabular}

Tabela 2. Fonte: Listas Nominativas de Habitantes de São Luiz do Paraitinga (1798-1818)

Entretanto, ainda que a pequena posse de escravos tenha sido predominante numericamente frente às demais faixas de propriedade, um exame detido acerca do número de cativos pertencentes aos médios e grandes plantéis nos revela uma realidade que, guardadas as devidas proporções e considerando as diferentes tipologias adotadas, se assemelha à encontrada em zonas que se notabilizaram como centros exportadores da monocultura colonial.

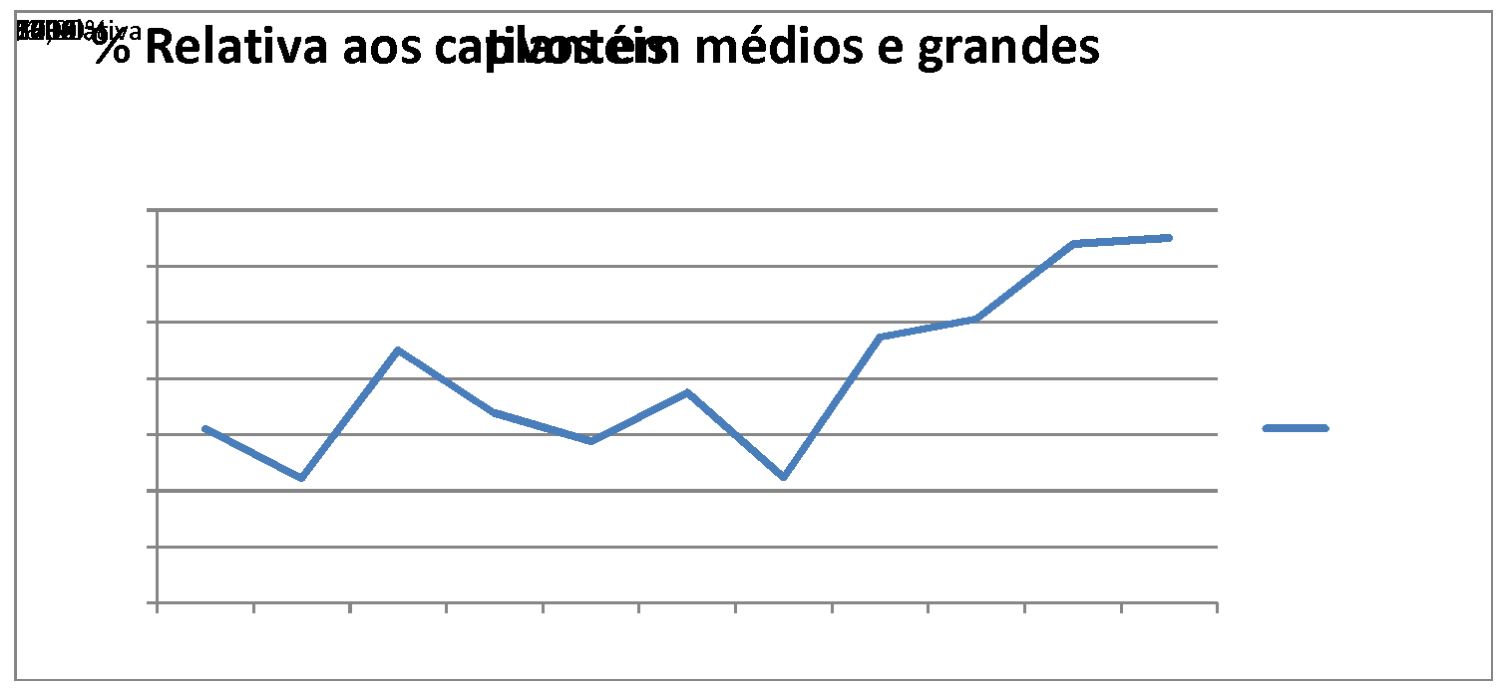

Gráfico 2. Fonte: Listas Nominativas de Habitantes de São Luiz do Paraitinga (1798-1818) 


\section{artigos}

Diego Alem de Lima

Como se percebe, com o passar dos anos e o aumento da entrada de cativos negros no âmbito da vila, cada vez mais indivíduos são listados como pertencentes às maiores faixas de plantéis aqui consideradas. Em recente artigo em que estuda a disseminação da escravidão ligada à plantação cafeeira em Bananal, Breno Moreno atenta para um fenômeno semelhante: com o passar do tempo, a propriedade escrava tornase cada vez mais concentrada nas mãos dos grandes proprietários (MORENO, 2019).

É bem verdade que a classificação das faixas de plantéis utilizadas pelo autor em seu estudo contrastam com a aqui adotada. Entretanto, se considerarmos a natureza singular da economia abastecedora de São Luís, pode-se trabalhar com a hipótese de que o quadro observado em nossos dados seja um equivalente ao diagnóstico estabelecido para algumas áreas exportadoras durante o século XIX. Hipótese que necessita de maior desenvolvimento para sua comprovação.

Mas já nos é possível afirmar que, nesse contexto pouco ligado à agricultura monocultora de exportação, a compra de braços cativos para o trabalho no meio agrícola não só era possível, como era caracterizada por um quadro onde a maioria dos proprietários detinha a minoria dos escravos declarados.

Restam-nos as perguntas: como se configurava a rede mercantil na qual estava inserido o pequeno povoado? Quais eram os principais gêneros vendidos por seus habitantes? E para quais localidades eram exportados tais artigos? Para respondê-las, lançaremos mão de um conjunto secundário de fontes, os Mapas Estatísticos de Comércio, que condensam as informações estatísticas extraídas das listagens, sobretudo os referentes à balança de comércio.

As exportações de excedentes produzidos na vila sempre tiveram como destino três localidades que variaram em importância ao longo do tempo: o Rio de Janeiro foi 


\section{artigos}

\section{Prover e acumular}

sempre o principal comprador de gêneros; Paraty e Ubatuba, respectivamente, são as outras duas vilas compradoras. Entretanto, é possível identificar uma alteração no perfil dos produtos comercializados ao longo do tempo.

Quando do começo de nossas análises (1798), os principais produtos a compor a pauta de exportações da paróquia eram o toucinho e o tabaco, em ordem de importância. Entretanto, sobretudo após o ano de 1808, a participação do toucinho na balança comercial decaiu bruscamente e de forma quase linear até o fim do período, sendo substituído pelos porcos vivos, que se tornaram o principal produto vendido, seguido pelo tabaco. O açúcar praticamente deixou de ser produzido na vila com o intuito de ser vendido, perdendo por completo sua importância nas trocas comerciais. Ao que parece, a vila se especializou, ao longo do tempo, na produção de tabaco e criação de porcos vivos.

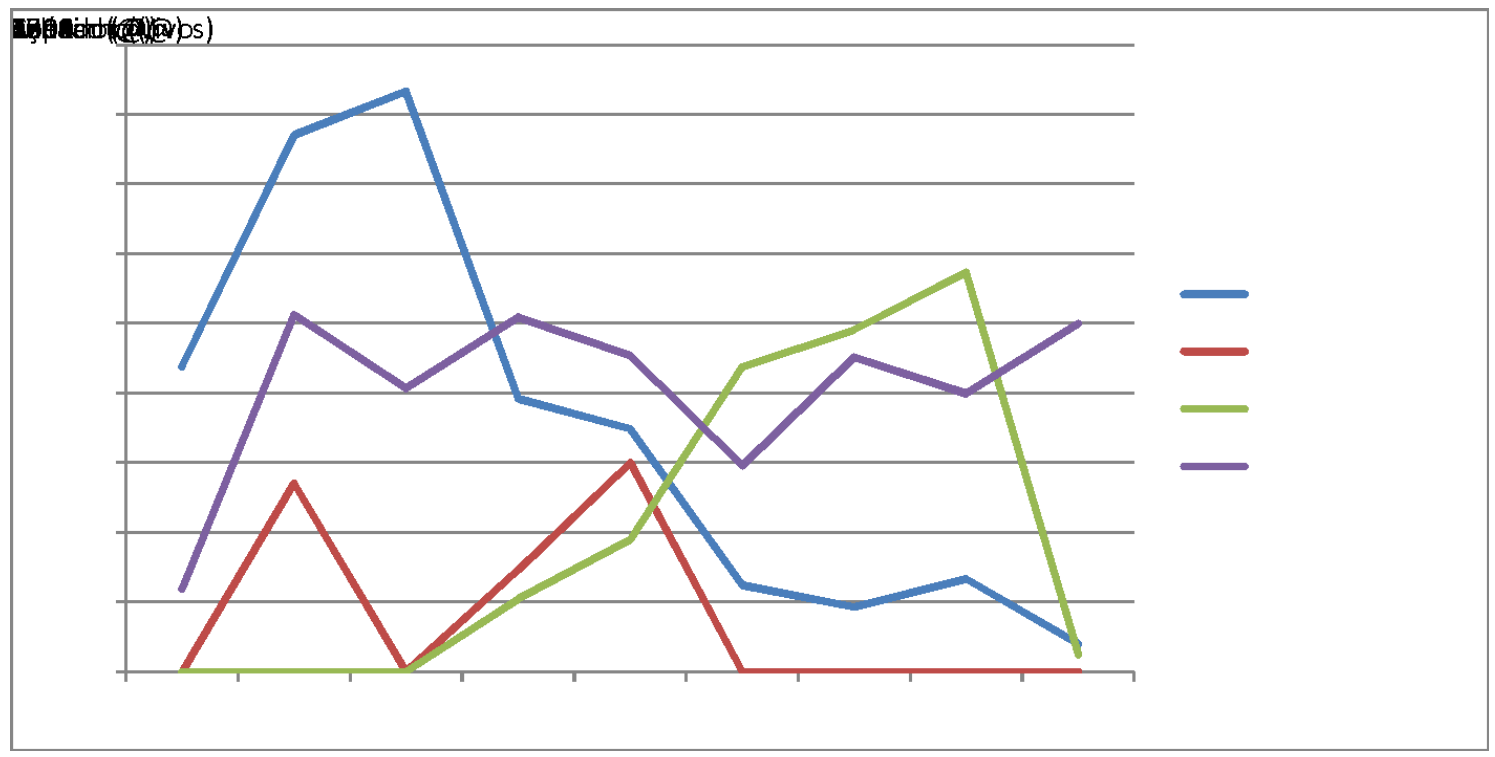

Gráfico 3: Artigos exportados pela paróquia ano a ano. Fonte: Listas Nominativas de Habitantes de São Luiz do Paraitinga (1798-1818) 


\section{artigos}

\section{Diego Alem de Lima}

A exportação de tabaco aparece como uma constante do universo econômico da vila durante o período, enquanto a criação e venda de porcos vivos seriam uma resposta a uma conjuntura, um estímulo externo. Quando cruzamos o volume de artigos exportados e as vilas para onde eram destinados, o quadro torna-se mais claro. Com o passar do tempo, o Rio de Janeiro se tornou o destino da majoritária produção comercializada pela paróquia de São Luís. Quase a totalidade dos capados vivos exportados pela paróquia era destinada à capital da colônia, bem como a produção intermitente de açúcar.

Trabalhamos aqui com a hipótese de que, com o desenvolvimento urbano e demográfico do Rio de Janeiro após ter se tornado capital colonial (1763), houve um significativo crescimento da demanda local por gêneros básicos. Isso teria criado uma rede de abastecimento substancialmente lucrativa, na qual estaria inserida São Luís do Paraitinga, o que tornava possível a acumulação de capital na forma de cativos, a partir de trocas favoráveis na balança comercial.

O Rio de Janeiro teve papel importante no abastecimento das regiões mineradoras, entretanto, com o declínio da extração aurífera das Gerais, os papéis teriam se invertido: as regiões limítrofes à capital teriam se especializado cada vez mais no cultivo de gêneros de exportação (durante o chamado Renascimento Agrícola ${ }^{3}$ ) e a lavoura de abastecimento teria perdido espaço (CAMPOS, 2010, p 25-27). A carência de gêneros básicos teria se agravado ainda mais com a transferência da corte portuguesa para a

\footnotetext{
3 O conceito de Renascimento Agrícola se refere ao fôlego renovado adquirido pelo setor agrícola da economia colonial, entre o fim do século XVIII e o início do século XIX. Múltiplas são as causas apontadas para esse movimento valorativo, como o aumento da demanda internacional por produtos como o açúcar, bem como do incremento do mercado interno, devido ao desenvolvimento demográfico e social observado ao longo do XVIII em diferentes regiões.
} 


\section{artigos}

\section{Prover e acumular}

colônia, em 1808. É possível observar como as vendas de tabaco e capados vindos de São Luís aumentam após a data, bem como a entrada de negros escravos no universo da vila.

Como tem demonstrado a produção recente acerca dos mercados internos coIoniais, a virada do século XVIII para o XIX é marcada, por diferentes motivos, pela valorização de determinados gêneros agrícolas (chamada, por vezes, de Renascimento Agrícola). Em primeiro lugar, no que se refere aos quadros mais gerais da conjuntura atlântica no recorte - que em grande parte determina-se pelos desdobramentos revolucionários em solo europeu (HOBSBAWM, 2012) -, a rebelião escrava Haitiana foi responsável pela desarticulação produtiva de uma das principais economias fornecedoras de açúcar e café no mercado global (MARQUESE, 2013, p.296-297), fazendo com que a cotação internacional dos referidos artigos se tornasse mais atrativa para os produtores da América lusitana. Assim, tornou-se possível a retomada rentável da produção em grande escala desses artigos de exportação na porção sudeste na colônia, como já discutido nas primeiras seções do presente projeto.

Em segundo lugar, somando-se às questões conjunturais supracitadas, o recorte por nós escolhido também se destaca pelas profundas alterações de nível mais local nas quais se viu inserida a vila de São Luiz. A transferência da corte lusitana para o Rio de Janeiro (principal mercado comprador da pequena vila) em decorrência das guerras napoleônicas representou um momento de profunda inflexão nos mais variados sentidos, sobretudo para os mercados regionais que aqui nos interessam. De partida, estima-se que a população da capital tenha dobrado entre os anos de 1808 e 1821 (MARTINS, 2008, p.1). A cidade sofreu tamanhas transformações nesse contexto que se transformou em um dos principais centros urbanos e comerciais do Atlântico Sul. Como argumenta Martins, a necessidade de atender emergencialmente a esse estupendo incremento na demanda fez com que uma série de recursos fosse mobilizada 


\section{artigos}

Diego Alem de Lima

para tornar viável tal tarefa (MARTINS, 2008). Em interessante artigo, Fábio Pesavento demonstra, a partir dos dados acerca das receitas extraídas pela coroa da taxação comercial nos portos fluminenses, como o fluxo comercial da capital se multiplicou enormemente durante as primeiras décadas do XIX (PESAVENTO, 2018).

Segundo Marcondes, além de ter se tornado o principal polo escoador de gêneros de exportação que passaram a dominar a paisagem econômica do centro-sul colonial entre o XVIII e o XIX, a capitania/província do Rio de Janeiro também figurou entre os principais produtores de tais gêneros, quadro comprovado pelo incremento substancial no número de engenhos de açúcar em seu território no período (MARCONDES, 1995, p.238-247). Mais do que isso, a cidade suplantou as regiões mineradoras como principal fomentadora dos mercados de abastecimento regional, não apenas por ser a principal fonte de demanda de gêneros básicos, mas também por terem partido dali os maiores esforços para a construção de novos canais de comunicação e transporte que viabilizassem a integração regional (MARCONDES, 2001, p. 41-77).

Logo, a massiva entrada de cativos negros impulsionada pela retomada das lavouras exportadoras na virada do século XVIII para o XIX traduziu-se em um incremento demográfico substancial em áreas como o Vale do Paraíba (MARCíLIO, 2000), onde se localiza a vida de São Luiz. Assim, a demanda por gêneros de abastecimento que pudessem sanar as necessidades dessa população em crescimento se viu aquecida. Ao mesmo tempo, a chegada da Corte portuguesa à capital do Vice-Reino fomentou violentamente o já relevante crescimento da cidade fluminense, em termos quantitativos, com a introdução de milhares de novos moradores no universo citadino. Também se alteraram aspectos qualitativos, com o fomento de novas redes e circuitos de abastecimento, a formação de novas elites comerciais que passaram a controlar tal tráfego de gêneros e a elevação no próprio nível de consumo da sociedade, posto que 


\section{artigos}

\section{Prover e acumular}

o patamar demandado por uma corte real europeia e seu aparato burocrático estava longe de ser trivial.

Assim, trabalhamos com a hipótese de que os pequenos produtores da vila de São Luiz do Paraitinga encontravam-se inseridos em uma conjuntura de extrema valorização dos gêneros produzidos. A alta dos preços do tabaco e dos derivados de suínos (exportados quase que integralmente para a capital, principal mercado comprador dos produtores de São Luiz) teria tornado possível a integração desses indivíduos em redes comerciais de média distância e de forma extremamente lucrativa, posto que conseguiram adquirir cativos no mercado negreiro (como supracitado, a acelerada taxa de crescimento da população cativa luizense nos fez descartar a ideia de um crescimento populacional endógeno, baseado na reprodução natural). Além disso, compravam-se cativos em idade produtiva e em sua maioria homens, portanto, de maior preço, o que fornece indícios para que possamos contestar a imagem tradicional veiculada pelos historiadores sobre áreas de abastecimento: caracterizadas costumeiramente pelo predomínio de escravos de menor valor agregado, como crianças e/ou muIheres, devido aos supostos baixos níveis de capitalização das economias locais (GUTIERREZ, 1987).

\section{Das trajetórias individuais: um estudo de casos.}

Como exposto acima, a pequena vila de São Luiz, fundada ao fim do século XVIII, no bojo de importantes alterações administrativas aplicadas à América portuguesa, passou por significativas transformações sociais e demográficas que estiveram atreladas ao processo de desenvolvimento da economia local. O ganho de vulto das atividades agropastoris e do comércio de excedentes produzidos, no contexto da exaltação do mercado local fluminense, tornou viável a acumulação de haveres econômicos por parte de setores da sociedade, com destaque para a recém cristalizada elite agrária que veio a concentrar a grande parte da riqueza produzida. 


\section{artigos}

Diego Alem de Lima

No entanto, como também buscamos evidenciar a partir da demonstração dos dados compilados, uma considerável parte da parcela pobre da população, em seu grosso composta por pequenos roceiros e plantadores de roçados, logrou acrescer seus meios a partir da venda do saldo produzido. Como bem argumenta Bacellar , a diferenciação entre lavradores que possuíam ou não a mão de obra cativa entre as suas possibilidades é elemento crucial para o entendimento das reais dimensões e potencialidades do tão desconhecido mercado interno colonial, pois, como sabemos, tal parcela social era extremamente heterogênea e as trajetórias individuais variam sobremaneira de domicílio para domicílio. Resta-nos agora buscar desvendar as estratégias e linhas de ação desenvolvidas e postas em prática por esses indivíduos no passado.

Para tanto, utilizaremos as fichas domiciliares confeccionadas a partir dos dados inventariados nas listas nominativas aqui abordadas. Concentramo-nos apenas nos núcleos familiares pertencentes à parcela dos pequenos escravistas que, como já dito, possuíam, em algum momento do recorte proposto, até cinco cativos em suas senzalas.

Foram produzidas cerca de 60 fichas individuais, a partir do modelo exposto no início de nosso trabalho. Entretanto, foram localizados diversos outros casos com potencial analítico entre os domicílios catalogados em nosso banco de dados, mas que não puderam ser examinados de forma mais detida pela falta de tempo disponível, posto que a montagem inicial do banco consumiu grande parte do período da pesquisa. Esses casos potenciais serão contemplados em etapas futuras desta pesquisa.

Além disso, é importante lembrar que, pelas dificuldades de produção dos maços de população (ausência de padronização; longas distâncias e incríveis dificuldades de locomoção, etc), bem como pelas próprias características contextuais de sua feitura 


\section{artigos}

\section{Prover e acumular}

(onde saber a idade não era crucial como nos dias de hoje; ocultar a presença de homens no domicílio se fazia necessário para se esquivar dos recrutamentos; subdeclarar os bens era uma estratégia para driblar a tributação) (BACELLAR,2008), as informações aqui expostas devem ser interpretadas a partir da ideia de que se tratam de estimativas que nos servem como referências para identificar movimentos na sociedade.

A primeira característica que salta aos olhos quando trazemos à luz o conjunto das fichas, é a íntima relação assumida entre a acumulação de cativos por pequenos produtores, e o comércio de gêneros básicos (notoriamente o tabaco e os porcos) com as praças compradoras da vila de São Luiz. Como já especulamos nas reflexões apresentadas, essa se mostrou ser uma condição quase indispensável para tornar possível a aquisição de cativos no mercado de mão de obra. Ou seja, a simbiose entre o pequeno produtor e a agricultura comercial mostrou-se fulcral e ponto comum dessas trajetórias de vida. A porcentagem relativa aos casos em que a ocupação do chefe de domicílio apareceu diretamente ligada às atividades agrícolas foi de $88,7 \%$ dos casos analisados.

O caso do lavrador Joaquim José Pinto parece ser uma típica trajetória de sucesso na acumulação de reservas. Listado em 1798 como roceiro de lavoura que "vende na terra", o homem de 41 anos contava, em sua casa, com a ajuda de sua esposa Margarida e de seus cinco filhos (um deles com apenas três anos de idade). Naquele ano, declarou ter produzido dezesseis arrobas de fumo, que vendeu. Já no ano de 1802, o agricultor catalogou uma produção de trinta arrobas de tabaco, demonstrando certo incremento na produção. Até que, em 1804, Joaquim já apresentava a posse de dois cativos homens em franca idade produtiva, bem como uma colheita ampliada de fumo; cinquenta arrobas. Com o passar dos anos, o agricultor chegou a acumular mais três escravos, e sua produção seguiu em evidente ampliação (sendo listado, em 1816, como dono de engenho produtor de aguardente). 


\section{artigos}

\section{Diego Alem de Lima}

Também esse parece ser o caso de José da Costa Ribeiro. Listado com 50 anos em 1798, o agricultor produzia em seu domicílio alguma quantidade de toucinho e tabaco (foram vinte arrobas de cada no referido ano) com a ajuda de sua esposa, Quitéria (50 anos), seus três filhos que possuíam entre 13 e 15 anos, e a escrava Rosa, de 16 anos. Já em 1802, o agricultor possuía já quatro cativos, todos em idade produtiva, chegando, em 1818, a um plantel de cinco cativos, sendo que quatro deles se encontravam em idades produtivas.

Afora os casos de domicílios de agricultores, surgem, com o passar do tempo, indícios de enriquecimento alcançado por indivíduos que desempenhavam aquilo que podemos chamar de atividades "satélites" da lavoura comercial de mantimentos. Para esses casos, levantamos a hipótese de que, com o incremento da atividade comercial entre a vila e as áreas circunvizinhas, a lucratividade dos serviços ligados à venda desses gêneros também se viu ampliada, em um efeito multiplicador "cascata" que transcende as atividades centrais. São os casos de tropeiros, negociantes, vendeiros e alfaiates que se aproveitaram da onda de prosperidade e crescimento que atingiu o mercado e a sociedade local no geral. Assim, Joaquim Teixeira (Joaquim Ferreira da Costa), listado como tropeiro durante todo o recorte abordado, conseguiu, em 1816, então com 43 anos, adquirir o cativo João, congo de 24 anos.

Vários são os casos de domicílios que, a exemplo dos supracitados, enriqueceram e vislumbraram acumular reservas suficientes para a montagem de uma escravaria. Entretanto, ainda que minoritários, fomos capazes de encontrar casos de fogos que não se encontravam diretamente relacionados ao comércio de gêneros de abastecimento, mas que também demonstraram capacidade de acumulação econômica. 


\section{artigos}

\section{Prover e acumular}

É o que se sucedeu com José Antônio dos Santos, alfaiate que, em 1806, então com 34 anos, casou-se com a então viúva Maria Gomes, listada com 25 anos. O chefe passou, a partir de então, a comandar uma escravaria de quatro indivíduos, trazida por sua esposa, que herdara tais posses com a morte de seu primeiro marido. Da mesma origem é o acúmulo apresentado pelo roceiro Antônio de Sousa Barbosa. Seu segundo casamento, ocorrido já como sexagenário e selado com a esposa Maria, foi acompanhado da vinda de 4 cativos, os quais foram recebidos pela esposa como herança em seu primeiro matrimônio.

Assim, a herança, mais do que o casamento, aparece como estratégia viabilizadora do acúmulo de capital. Esse é, marcadamente, o caso da maioria das mulheres que aparecem na chefia de domicílios escravistas. Geralmente já com idade avançada, as viúvas acabavam por herdar, juntamente com os filhos, o patrimônio econômico antes encabeçado pelo marido. Exemplo disso é o domicílio da viúva Francisca Leme de Oliveira que, com o falecimento do cônjuge, herdou os três escravos de sua senzala. Infelizmente, o pequeno número de casos como esse incluídos em nossas fichas impossibilita análises mais detalhadas quanto à manutenção desse capital por parte de tais mulheres após a morte de seus maridos.

Talvez ainda mais importante que as ocupações declaradas por cada um desses pequenos domićlios escravistas seja o perfil dos cativos adquiridos durante o ciclo de vida da família. Quais seriam os atributos qualitativos dos indivíduos escravos introduzidos nesses fogos durante o intervalo? As informações compiladas nas listas nos permitem levantar alguns indícios e apontamentos.

Há, contudo, que se fazer um breve apanhado do que tem sido levantado pela historiografia que trata das áreas abastecedoras de nosso passado. A partir de pesquisas robustamente embasadas em dados empíricos e documentações seriadas, chegou- 


\section{artigos}

\section{Diego Alem de Lima}

se ao relativo consenso de que, em núcleos populacionais distanciados das zonas exportadoras, o perfil das escravarias tenderia a assumir determinado padrão, qual seja: um relativo equilíbrio de sexos entre os cativos. Em tais localidades, a reprodução natural da massa escrava teria grande importância relativa na manutenção dos plantéis, fator que seria um dos responsáveis pelo equilíbrio supracitado. Além disso, era maior o peso relativo das escravas mulheres, sobretudo nas faixas etárias de idades produtivas (situação aprofundada pelo possível sub-registro de homens na fuga do recrutamento militar), e dos cativos de tenra idade, posto que nessas áreas, supostamente menos capitalizadas, os players tenderiam a assumir a estratégia de optar por indivíduos de menor valor agregado, casos das escravas femininas e/ou crianças ${ }^{4}$.

Assim, ao analisar as pequenas escravarias sorocabanas, Bacellar chega a razões de masculinidade próximas a 91, ou seja, encontrando um franco predomínio das escravas mulheres frente aos homens. Da mesma forma, Gutierrez (1987) e Marcílio (1986), também abordando zonas afastadas das atividades exportadoras, encontram padrões de equilíbrio entre sexos bastante estabilizados. Mais do que isso: no geral, a população escrava encontrada nessas áreas revela-se marcadamente jovem, apresentando, como visto em Gutiérrez, proporções de até $40 \%$ dos cativos em idade abaixo da produtiva (0-15 anos) (GUTIERREZ, 1987).

Porém, os números extraídos para as 60 escravarias aqui tratadas nos revelam uma realidade um tanto quanto surpreendente para a vila de São Luiz. No recorte abordado, foram listados, no total, 170 cativos no decorrer dos anos e nas diferentes senzalas observadas. Deste montante, $111(65,3 \%)$ eram cativos homens, ao passo que 59

\footnotetext{
4 GUTIÉRREZ, Horácio. Demografia escrava numa economia não-exportadora: Paraná, 1800-1830. Estudos Econômicos, 17 (2): 297-314. São Paulo: Fipe/USP, maio/ago. 1987.
} 


\section{artigos}

\section{Prover e acumular}

$(34,7 \%)$ eram mulheres. Já de início, percebemos que se trata de uma realidade um tanto quanto discrepante das citadas acima.

Aqui o equilíbrio entre os sexos parece não se manifestar tão plenamente no montante geral dos cativos listados. Mais do que isso, $41 \%$ do total dos escravos declarados eram homens em idade produtiva (14-50 anos), e 20\% desse total se tratavam de mulheres produtivas. Ao que parece, os pequenos produtores luizenses tinham acesso a uma escravaria majoritariamente composta por indivíduos em idade produtiva e com maioria masculina. Entretanto, a consideração do total dos cativos listados pode nos induzir a erros, posto que há a possibilidade do mesmo cativo ser contabilizado duas vezes, nas inúmeras migrações entre senzalas que podem ter ocorrido.

Passemos, então, à análise apenas dos primeiros cativos adquiridos pelos chefes de domicílios dessas 60 escravarias. Aqui, consideramos apenas os escravos acerca dos quais foi possível afirmar, com segurança, que foram os primeiros do recorte e adquiridos no mercado, tendo sido deixados de fora da contabilização os recém nascidos e os escravos que já se encontravam nos domicílios quando da primeira listagem daquele fogo. Delineamos, assim, um universo de 40 "primeiros escravos" (referentes a 34 das 60 unidades). É bem verdade que se trata de um espaço amostral bastante reduzido sobre o qual é difícil construir generalizações ou arguir padrões demográficos. Entretanto, os dados nos servem como indicativos.

Desses quarenta indivíduos, uma impressionante parcela de 31 (77,5\%) eram homens, com uma idade média de 22,8 anos. Entre as 9 cativas femininas, a idade média encontrada foi de 15,7 anos. Acreditamos que as diferenças entre as idades se deva ao fato de que cativos homens tendem a ser proporcionalmente mais procurados no mercado negreiro, que seleciona escravos com idade mais elevada, enquanto a população feminina tem seu crescimento mais atrelado ao desenvolvimento vegetativo natural da 


\section{artigos}

Diego Alem de Lima

população. Os indícios apontam para uma capacidade sui generis dos pequenos agricultores da vila para se inserirem no mercado negreiro local. Diferente do que se poderia imaginar, esses roceiros principiam suas escravarias já recorrendo a escravos masculinos e em idade produtiva.

Quando passamos a considerar a massa geral dos cativos adquiridos no mercado, novamente, os indícios apontam para o mesmo caminho. Ao todo, foram detectadas 109 compras ao longo dos 20 anos. Setenta e nove desses indivíduos pertenciam ao sexo masculino, enquanto que apenas 30, ao feminino. Novamente, a discrepância entre os sexos se manifesta. É legítimo aventar, também, a partir dos dados apresentados, que a naturalidade desses cativos não tendesse grandemente para o lado nacional, posto que grande parte deles era adquirida via mercado negreiro.

Entretanto, uma forma ainda mais segura de depreender o real cenário concretizado no contexto desses pequenos produtores, é observar a listagem, para cada ano isoladamente, de indivíduos cativos para ambos os sexos. Aqui, o quadro pode ser visualizado de forma mais cristalina e o equilíbrio da distribuição ao longo dos anos, meIhor compreendido:

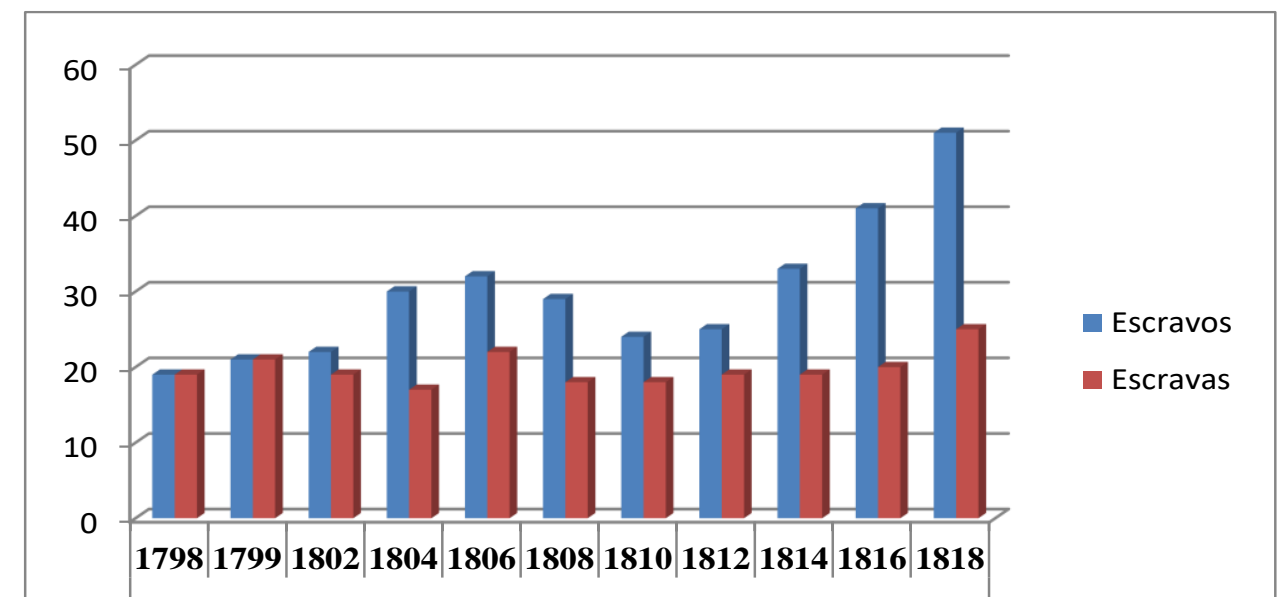

Gráfico 4. Fonte: Listas Nominativas de Habitantes de São Luiz do Paraitinga (1798-1818) 


\section{artigos}

\section{Prover e acumular}

O gráfico acima registra de forma mais visível a dinâmica demográfica entre sexos da composição das escravarias observadas ao longo dos anos. Percebe-se que, nos primeiros anos do recorte, os conjuntos configuram-se a partir de um perfeito equilíbrio entre os sexos.

Quando avançamos no tempo, passa a haver um descompasso cada vez maior na razão de masculinidade apresentada. Aqui, é possível formular duas hipóteses distintas, que carecem de validação a posteriori. A primeira delas é a ideia de que, a partir da primeira década dos 1800, a oferta de negros no mercado escravista se encontrava em expansão, fazendo com que os preços se tornassem mais acessíveis às camadas mais baixas dos produtores. A segunda parte do pressuposto de que, no período em questão, o aquecimento do comércio de abastecimento fez com que as atividades se tornassem lucrativas o bastante para que os pequenos roceiros pudessem integrar-se ao mercado de braços cativos.

E mais, ao que parece, após o ano de 1806, há um período (que se estende até 1814) marcado pela perda de braços nas escravarias dos pequenos agricultores. É possível que esses cativos estivessem sendo comprados por grandes escravocratas locais, incentivados pelo boom da demanda com a vinda da Corte portuguesa, e abocanhando ferozmente os cativos disponíveis no universo local. A aparente perda de indivíduos também aconteceu ao mesmo tempo em que os pequenos escravistas passavam por dificuldades para adquirir cativos, tornando plausível a hipótese de que esses oito anos teriam sido marcados por uma supervalorização do braço negro.

As informações mostradas no Gráfico 4 corroboram essa ideia, posto que o intervalo entre os anos de 1808 e 1815 é marcado por uma notável explosão das exportações de porcos vivos e de tabaco. Com isso, criava-se, ao mesmo tempo, o mercado 


\section{artigos}

Diego Alem de Lima

lucrativo para os pequenos produtores, e o preço dos cativos elevados demais para que pudessem ser comprados.

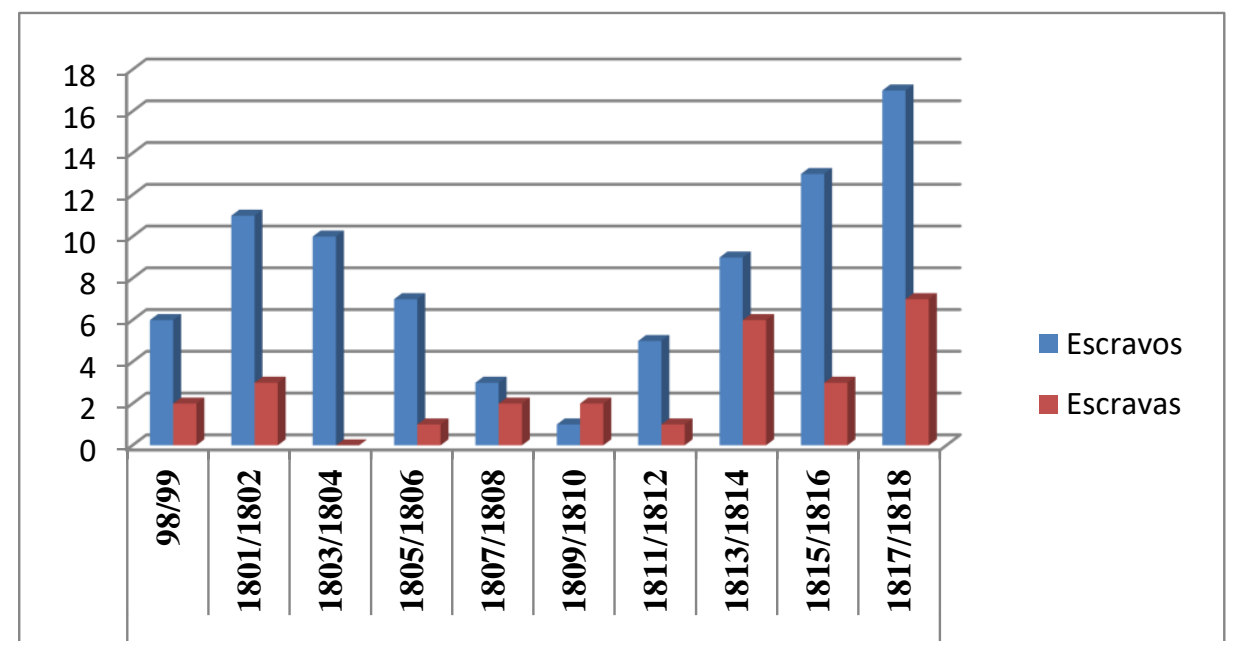

Gráfico 5. Fonte: Listas Nominativas de Habitantes de São Luiz do Paraitinga (1798-1818)

O gráfico acima, por fim, reforça as hipóteses formuladas até o momento. Em primeiro lugar, é possível enxergar de forma mais pormenorizada a capacidade dos pequenos escravistas da vila de adquirirem cativos homens, comprovadamente mais valorizados no mercado negreiro. Além disso, parece haver, entre os dois períodos de expansão da compra de escravos (1798-1802 e 1812-1818) um "vale" de decadência no acesso à mão de obra via mercado, o que vai ao encontro do que já formulamos anteriormente. Após esse meio tempo, há a retomada na acessibilidade da compra escravista, e os motivos dessas oscilações necessitam de pesquisas mais aprofundadas para poderem ser esclarecidos.

Entretanto, algumas outras perguntas permanecem sem respostas ou até mesmo indícios satisfatórios: como estariam se comportando os pequenos escravistas no momento de contração da capacidade de compra da mão de obra? Estariam eles, 


\section{artigos}

\section{Prover e acumular}

de alguma forma, estimulando o desenvolvimento endógeno das escravarias? A queda na oferta de braços estaria ligada à absorção desses cativos por parte dos grandes produtores locais, ou a fonte da demanda elevada estaria mais ligada a questões externas à própria vila? Teria havido flutuações significativas no tráfico negreiro no decorrer do recorte aqui abordado (com consequentes flutuações nos preços) ${ }^{5}$ ? Como funcionou o mercado interno de escravos das vilas do interior paulista no passado, posto que o grau de monetização da economia era precário? Essas e muitas outras perguntas essenciais para a compreensão de nosso passado escravista continuam sem respostas e carecem de mais pesquisas sistemáticas acerca dos mercados abastecedores.

\section{Conclusões}

Como buscamos evidenciar, a pequena vila de São Luiz do Paraitinga, fundada na segunda metade do século XVIII e localizada no Vale do Paraíba paulista, notabilizouse, nas primeiras décadas do XIX, pela íntima relação de abastecimento regional desenvolvida com os núcleos populacionais circunvizinhos, sobretudo a capital do Vice-Reino, o Rio de Janeiro.

Essa relação econômica marcou estruturalmente o cenário demográfico da vila. Seu crescimento populacional esteve, durante o período estudado, profundamente marcado pelo afluxo de cativos negros trazidos para atuar na dinâmica econômica agrícola local, evidencia que vai de encontro com as argumentações da historiografia mais clássica, segundo a qual o mercado interno colonial brasileiro seria uma esfera marginal e estagnada, sem poder econômico relevante. Esses braços, que adentraram a esse

\footnotetext{
5 Sobre a estreita relação existente entre as flutuações do tráfico atlântico e a montagem das escravarias:

FLORENTINO, Manolo; GÓES, José Roberto. A paz das senzalas: Famílias escravas e tráfico atlântico c.1790- c.1850. São Paulo, Editora Unesp, 2017, $1^{\text {aed. }}$
} 


\section{artigos}

Diego Alem de Lima

universo em ritmo crescente, não se distribuíram de forma igualitária em meio aos habitantes do povoado: cerca de $75 \%$ dos cativos estavam concentrados nas mãos dos médios e grandes escravistas, extremamente minoritário.

Entretanto, o setor dos pequenos produtores também se mostrou capaz de, através do mercado, adquirir indivíduos escravizados. Nessa parcela da população estava localizada a maioria numérica dos escravistas locais. Mais do que isso, estabelecido um recorte de 60 escravarias que foram acompanhadas ao longo do período, demonstrou-se existirem indícios que fogem dos padrões encontrados pela historiografia para outras áreas abastecedoras: os pequenos produtores luizenses se mostraram capazes de adquirir cativos da melhor qualidade; aparentemente, os homens em idade produtiva dominaram o cenário dessas senzalas observadas, ainda que variando ao longo do tempo por conta da dinâmica mais abrangente dos mercados.

Aqui, acreditamos que a hipótese que melhor explica essa notável capacidade de acumulação de capitais seja a ideia de que, com o incremento excepcional da demanda por gêneros de abastecimento na capital colonial, sobretudo após a chegada da Corte portuguesa em 1808, a valorização do comércio de produtos de primeira necessidade fez com que os lucros nessas atividades fossem tamanhos que viabilizassem a construção desses patrimônios, ainda que diminutos (efeito multiplicador) ${ }^{6}$. Os agricultores que conseguiram integrar-se a esse circuito de acumulação lograram, ao longo do tempo, construir suas escravarias e diferenciar-se da esmagadora maioria de seus pares, que jamais viriam a atingir tal grau de enriquecimento. Porém, essas e muitas

\footnotetext{
${ }^{6}$ Sobre o Efeito Multiplicador em economias de abastecimento, ver: SLENES, Robert W. Os múltiplos de Porcos e Diamantes: A Economia Escrava de Minas Gerais no Século XIX, São Paulo: Estudos Econômicos, v.18, n.3, 1988, p.449-495.
} 


\section{artigos}

Prover e acumular

outras hipóteses acima desenvolvidas encontram-se em estágio prematuro e ainda sendo gestadas, carecendo de estudos mais aprofundados para sua comprovação.

A principal conclusão que tiramos dessa experiência é que estudos demográficos pontuais e bem localizados no tempo e no espaço revelam-se indispensáveis para que possamos fugir das generalizações tradicionais da historiografia. Além disso, nos mostram serem inválidas as tentativas de se explicar o sistema escravista brasileiro a partir de um modelo único. Como bem salienta Bacellar (BACELLAR, 2001) a imensidão de indícios existentes, ainda que com a escassez de estudos, demonstram que tal quadro único proposto por parte da historiografia, na verdade, se refere a uma realidade específica dos grandes centros monocultores, não sendo aplicável à grande maioria das realidades sociais que não apenas erigiram o nosso sistema escravista no passado, mas moldaram também nossa sociedade presente (BACELLAR,2001).

\section{Referências Bibliográficas}

BACELLAR, Carlos A.P. Arrolando os habitantes no passado: as listas nominativas sob um olhar crítico. Locus: revista de história. Juiz de Fora, v. 14, n. 1, 2008.

Criando porcos e arando a terra: família e compadrio entre os escravos de uma economia de abastecimento (São Luís do Paraitinga, Capitania de São Paulo, 17731840). $3^{\circ}$ encontro Escravidão e Liberdade no Brasil Meridional, p.3. Acesso em: http://www.escravidaoeliberdade.com.br/site/images/Textos3/carlos\%20de\%20almei da\%20prado.pdf

O primeiro escravo: as famílias e suas estratégias para fugir da pobreza através dos registros das listas nominativas de habitantes da vila de Itu, capitania de São Paulo. Trabalho apresentado no XIX Encontro Nacional de Estudos Populacionais, ABEP, realizado em São Pedro/SP - Brasil, de 24 a 28 de novembro de 2014.

Viver e Sobreviver em uma vila colonial: Sorocaba, séculos XVIII e XIX. São Paulo: Annablume/ FAPESP, 2001.

BELOTTO, Heloísa L. Autoridade e Conflito no Brasil colonial: o governo do Morgado de Mateus em São Paulo (1765-1775). São Paulo: Alameda, 2007. 
BLAJ, Illana. A trama das tensões: o processo de mercantilização de São Paulo colonião (1681-1721). São Paulo: Humanitas/FFLCH-USP: FAPESP, 2002.

BORREGO, Maria Aparecida de M. A teia mercantil: negócios e poderes em São Paulo colonial (1711-1765). Tese (doutorado) - Faculdade de Filosofia, Letras e Ciências Humanas da Universidade de São Paulo. São Paulo: 2006.

CAMPOS, Pedro Henrique Pedreira. A contribuição da História do Abastecimento para a historiografia brasileira. In: SIMPÓsIO NACIONAL DE HISTÓRIA, 23, 2005, Londrina. Anais do XXIII Simpósio Nacional de História - História: guerra e paz. Londrina: ANPUH, 2005.

CANABRAVA, Alice Piffer. 0 desenvolvimento da cultura do algodão na província de São Paulo, 1861-1875. Universidade de São Paulo, 1951.

CANDIDO, Antônio. Os parceiros do Rio Bonito. São Paulo: Edusp, 12ª edição, 2017.

EISENBERG, Peter. Homens Esquecidos: Escravos e Trabalhadores Livres no Brasil - século XVIII e XIX. Campinas: Editora da Unicamp, 1989.

FLORENTINO, Manolo; GÓES, José Roberto. A paz das senzalas: Famílias escravas e tráfico atlântico c.1790- c.1850. São Paulo, Editora UNESP, 2017, $1^{\text {a ed. }}$

FRAGOSO, João; FLORENTINO, Manolo. O arcaísmo como projeto: Mercado atlântico, sociedade agrária e elite mercantil em uma economia colonial tardia. Rio de Janeiro 1790-1840. Civilização Brasileira, 2001.

GUTIÉRREZ, Horácio. Demografia escrava numa economia não exportadora: Paraná, 1800-1830. Estudos Econômicos, 17 (2): 297-314. São Paulo: FIPE/USP, maio/ago. 1987.

HOBSBAWM, Eric J. A Era das Revoluções - 1789-1848. Paz e Terra, 2012.

LUNA, Francisco Vidal \& COSTA, Iraci del Nero da. Posse de Escravos em São Paulo no Início do Século XIX. Estudos Econômicos, São Paulo, IPE-USP, 13(1):211-21, 1983.

São Paulo: População, Atividades e Posse de escravos em Vinte e Cinco Localidades (1777-1829). Revista Estudos Econômicos, São Paulo, V.28, N-1, JaneiroMarço de 1998

; KLEIN, Herbert. Escravismo no Brasil, São Paulo: Edusp, 2010. 


\section{artigos}

Prover e acumular

; KLEIN, Herbert. Evolução da sociedade e economia escravista de São

Paulo, de 1750 a 1850. São Paulo: Edusp, 2006, p.107-108.

MARCÍLIO, Maria Luiza. Crescimento demográfico e evolução agrária paulista (1700-1836). São Paulo: Hucitec/EDUSP, 2000.

Caiçara: terra e população. Estudo de demografia histórica e da história social de Ubatuba. São Paulo: Paulinas, 1986.

Crescimento demográfico e evolução agrária paulista (1700-1836). São Paulo: Hucitec/EDUSP, 2000.

MARCONDES, Renato Leite. Formação da Rede Regional de Abastecimento do Rio de Janeiro: a presença dos negociantes de gado (1801-1811). Topoi, Rio de Janeiro, 2001

MARQUESE, Rafael de B. Capitalismo, Escravidão e Economia Cafeeira do Brasil no longo século XIX. Saeculum, João Pessoa, Jul/Dez, 2013, p.296-297.

MARTINS, Roberto Borges. A transferência da Corte portuguesa para o brasil: impactos sobre as Minas Gerais. Anais do XIII Seminário sobre a Economia Mineira, 2008

MONT-SERRATH, Pablo Oller. São Paulo restaurada: administração, economia e sociedade e uma capitania colonial (1765-1802). São Paulo: Alameda, 2017.

MORENO, Breno A. S. (prelo do evento "Encontro Escravidão e Liberdade no Brasil Meridional" ocorrido entre 14 e 18 de Maio de 2019, em Florianópolis). A estrutura da posse de escravos no médio vale do Paraíba: Bananal, 1830-1880.

MOTTA, José Flávio. A demografia histórica no Brasil: contribuições à historiografia. Revista Brasileira de Estudos da População. Vol. 5, n. ${ }^{\circ} 1,1988$.

O advento da Cafeicultura e a Estrutura de Posses da Posse de Escravos (Bananal, 1801-1829). In: Estudos Econômicos, São Paulo, V.21, №3, 1991.

NOVAIS, Fernando A. Portugal e Brasil na crise do antigo sistema colonial (17771808), São Paulo: Hucitec, 1995.

PETRONE, Pascuale. A Região de São Luís do Paraitinga - Estudo de Geografia Humana. Revista brasileira de geografia, julho-setembro de 1959.

PESAVENTO, Fábio. A conjuntura econômica transatlântica durante o século XVIII: o caso do Rio de Janeiro. Acesso em: https://www.insper.edu.br/wpcontent/uploads/2018/08/pesavento-conjuntura.pdf 


\section{artigos}

Diego Alem de Lima

SAIA, Luis; TRINDADE, Jaelson B. São Luis do Paraitinga. Publicação $\mathbf{n}^{\circ} \mathbf{2}$ do CONDEPHAAT, 1977.

SALLES, Ricardo. E o vale era o escravo: Vassouras, século XIX. Senhores e escravos no coração do Império. Rio de Janeiro: Civilização Brasileira, 2008. 